Vol. 1, No. 2, pp. 147-156, (December 2020)

DOI: 10.21608 /aujes.2020.127572

Aswan University Journal of Environmental Studies (AUJES)

Online ISSN: 2735-4237, Print ISSN: 2735-4229

Journal homepage: https://aujes.journals.ekb.eg/

E-mail: AUJES@aswu.edu.eg

Original research

\title{
Cotes's Spiral Vortex in Extratropical Cyclone Bomb South Atlantic Oceans
}

Ricardo Gobato $^{1}$, Alireza Heidari ${ }^{2}{ }^{*}$, Abhijit Mitra ${ }^{3}$ and Marcia Regina Risso Gobato ${ }^{1}$

${ }^{1}$ Green Land Landscaping and Gardening, Seedling Growth Laboratory, 86130-000, Parana, Brazil.

${ }^{2}$ Faculty of Chemistry, California South University, 14731 Comet St. Irvine, CA 92604, USA.

${ }^{3}$ Department of Marine Science, University of Calcutta, 35 B.C. Road Kolkata, 700019, India.

Received: 22/9/2020

Accepted: 25/10/2020

(C) Unit of Environmental Studies and Development, Aswan University

Abstract:

The characteristic shape of hurricanes, cyclones, typhoons is a spiral. There are several types of turns, and determining the characteristic equation of which spiral the "cyclone bomb" (CB) fits into is the goal of the work. In mathematics, a spiral is a curve which emanates from a point, moving farther away as it revolves around the point. An "explosive extratropical cyclone" is an atmospheric phenomenon that occurs when there is a very rapid drop in central atmospheric pressure. This phenomenon, with its characteristic of rapidly lowering the pressure in its interior, generates very intense winds and for this reason it is called explosive cyclone, bomb cyclone. It was determined the mathematical equation of the shape of the extratropical cyclone, being in the shape of a spiral called "Cotes's Spiral." In the case of CB, which formed in the south of the Atlantic Ocean, and passed through the south coast of Brazil in July 2020, causing great damages in several cities in the State of Santa Catarina. With gusts recorded of $116 \mathrm{~km} / \mathrm{h}$, atmospheric phenomenon - CB hit southern Brazil on June 30, the beginning of winter 2020, causing destruction in its influence over. In five hours the CB traveled a distance of $257.48 \mathrm{~km}(159.99$ miles), at an average speed of $51.496 \mathrm{~km} / \mathrm{h}(31.998 \mathrm{miles} / \mathrm{h}) 27.81 \mathrm{knots}$, moved towards ENE, with a low pressure center of 986 mbar, 07:20 UTC, approximate location $35^{\circ} \mathrm{S} 45^{\circ} \mathrm{W}$, and 5 hours after 12:20 UTC had already grown and had a low pressure center of 972 mbar , approximate location $34^{\circ} \mathrm{S} 42^{\circ} 30^{\prime} \mathrm{W}$.

Keywords: Atmospheric phenomenon, Brazil, Cotes's Spiral, Cyclone bomb, Extratropical cyclone, Parana, Santa Catarina, Rio Grande do Sul, Winter.

\section{1- INTRODUCTION}

In mathematics, a spiral is a curve which emanates from a point, moving farther away as it revolves around the point. (Vossler, 1999; Casey, 2001; Sharipov, 2011.; León \& Rodrigues, 1989).

The characteristic shape of hurricanes, cyclones, typhoons is a spiral (Vasquez, 2002; Paulescu et al., 2012; Bluestein et al., 2008; Santurette \& Georgiev, 2005). There are several types of turns, and determining the characteristic equation of which spiral the cyclone bomb CB (Gobato \& Heidari, 2020).

Corresponding authors*: E-mail addresses: Scholar.Researcher.Scientist@gmail.com; Alireza.Heidari@calsu.us 
The work aims to determine the mathematical equation of the shape of the extratropical cyclone, in the case of CB (Gobato \& Heidari, 2020), which formed in the south of the Atlantic Ocean, and passed through the south coast of Brazil in July 2020, causing great damages in several cities in the State of Santa Catarina. (Gobato \& Heidari, 2020).

An "explosive extratropical cyclone" is an atmospheric phenomenon that occurs when there is a very rapid drop in central atmospheric pressure. This phenomenon, with its characteristic of rapidly lowering the pressure in its interior, generates very intense winds and for this reason it is called explosive cyclone, bomb cyclone (Vasquez, 2002; Paulescu et al., 2012; Bluestein et al., 2008; Santurette \& Georgiev, 2005; Gobato \& Heidari, 2020).

With winds of $100 \mathrm{~km} / \mathrm{h}$ "explosive extratropical cyclone" left a trail of destruction in Santa Catarina, Paraná and Rio Grande do Sul on Tuesday, June 30, 2020. The phenomenon known as the "cyclone bomb" caused heavy rains, where gusts of wind destroyed houses, caused tree falls, debris and the destruction of the energy network, (Gobato \& Heidari, 2020) main Chapecó

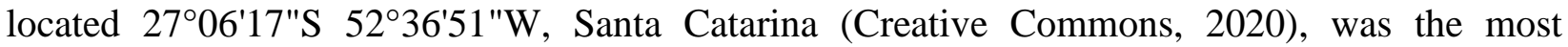
affected by cyclone.

The occurrence of cyclones is relatively common for the region at this time of year, but the recent phenomenon has been exacerbated by other meteorological and atmospheric factors. This phenomenon, with this feature to lower the pressure inside quickly generates very strong winds and so that name of explosive cyclones. For large-scale occurs, the tropical cyclones influence and are influenced by the weather and other atmospheric phenomena point of view, the call synoptic condition. A very intense circulation of heat and humidity from the North region, with emphasis on the Amazon and Bolivia, increased the occurrence of the cyclone more sharply, reaching Paraguay, Uruguay and northern Argentina, as well as the South-Brazilian coast (Vasquez, 2002; Paulescu et al., 2012; Bluestein et al., 2008, Santurette \& Georgiev, 2005; Gobato \& Heidari, 2020; (Rafferty, 2010; Krasny, 1986; Saffman, 1992; Sokolovskiy \& Verron, 2000; Gobato et al. 2016).

\section{DATE OF SYNOPTIC CHARTS OF CB AND SATELLITE IMAGES}

The cyclone pump (CB) (Gobato \& Heidari, 2020) with a low pressure center of 986 mbar, 07:20 UTC, approximate location $35^{\circ} \mathrm{S} 45^{\circ} \mathrm{W}$, and 5 hours after 12:20 UTC had already grown and had a low pressure center of 972 mbar, approximate location $34^{\circ} \mathrm{S} 42^{\circ} 30^{\prime} \mathrm{W}$. The $\mathrm{CB}$ traveled a distance of $257.48 \mathrm{~km}$ (159.99 miles), at an average speed of $51.496 \mathrm{~km} / \mathrm{h}(31.998 \mathrm{miles} / \mathrm{h}) 27.81$ knots, Figure (3), moved towards ENE.

To plot the graph of Figure (5), Figures (1-3) were used to accompany the isobaric ones, where points of Figure (3) were used for 7:20 UTC and 12:20 UTC and in short straight lines.

The analysis of the images of the Figures (1-3) uses the methods (Vasquez, 2002; Paulescu et al., 2012; Bluestein et al., 2008, (Gobato et al., 2016; Whittaker \& McCrae, 1989; Crosta, 1992; Gobato \& Simões F., 2017; George, 1960; Yorke, 2010; Anderson, 1984).

The Figures (1) and (2) show the Synoptic Letters, from July 1, 2020, at 00:00 UTC and 12:00 UTC, respectively, from Navy Hydrography Center, Brazil's navy (Brazil's navy, 2020). The CB generated a low pressure 976 mbar inside it, 12:00 UTC, generating two atmospheric currents that moved at high speed. In a northwest-southeast direction, Bolivia and Paraguay, crossing the states of Parana and Santa Catarina, and this draft that hit the south of Brazil, which caused the 
Aswan University Journal of Environmental Studies (AUJES) 1 (2), pp. 147-156, (2020).

Online ISSN: 2735-4237, Print: ISSN 2735-4229. https://aujes.journals.ekb.eg/

destruction of the affected states. Another moving to Argentina, southwest-northeast direction, due to high area of high pressure (1022 mbar). Both enhanced the phenomenon.

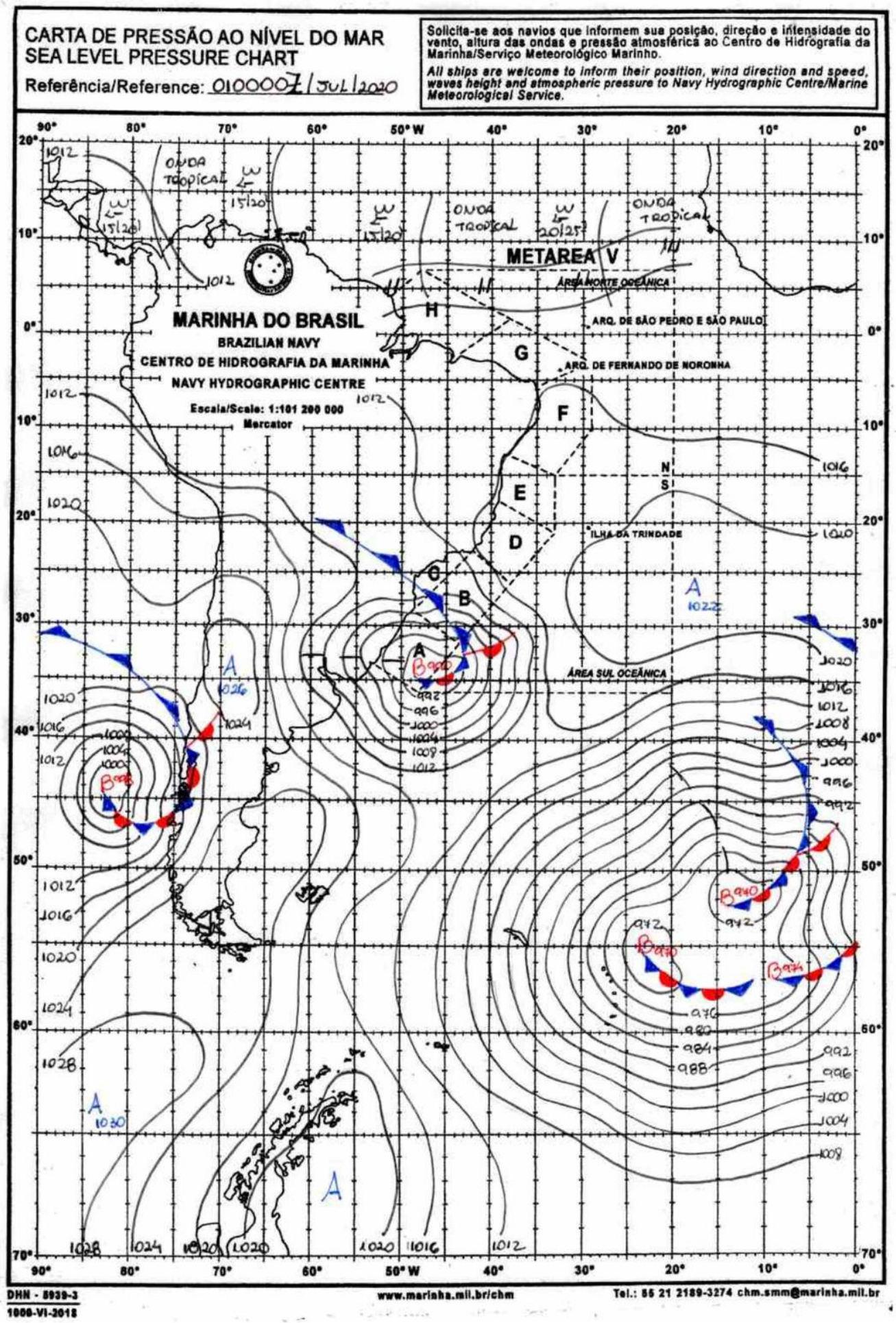

Figure 1. Synoptic Letters, from July 1, 2020, at 00h00 UTC. Navy Hydrography Center. Brazil's navy. Synoptic Letters. (Brazil's navy, 2020). 
Aswan University Journal of Environmental Studies (AUJES) 1 (2), pp. 147-156, (2020).

Online ISSN: 2735-4237, Print: ISSN 2735-4229. https://aujes.journals.ekb.eg/

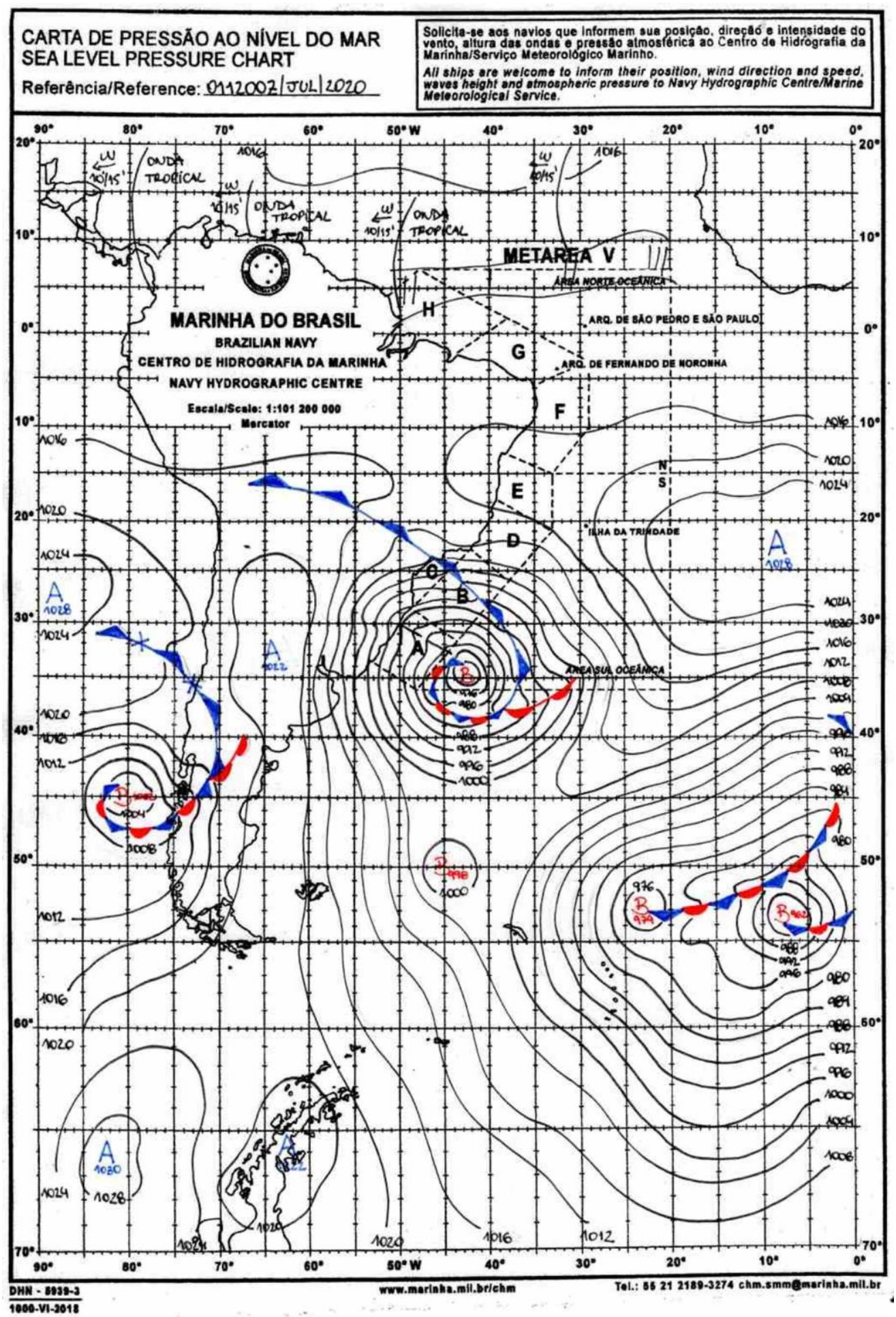

Figure 2. Synoptic Letters, from July 1, 2020, at 12h00 UTC. Navy Hydrography Center. Brazil's navy. Synoptic Letters. (Brazil's navy, 2020). 


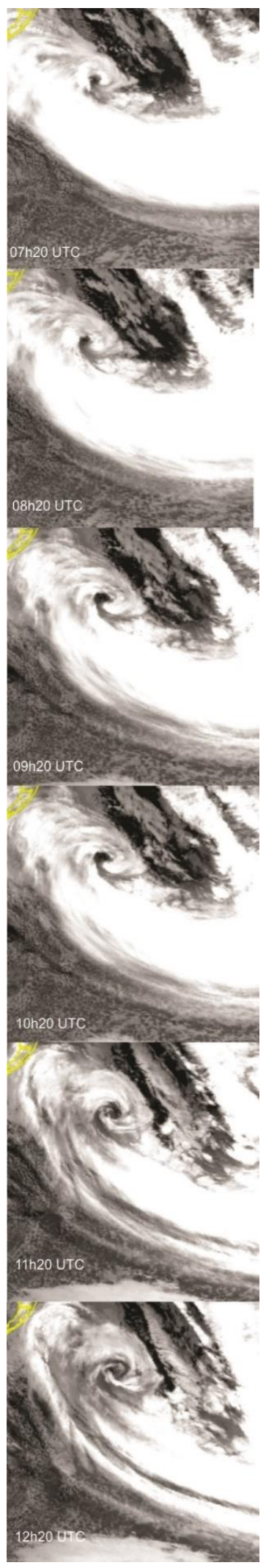

Figure 3. Image of the CB moving to the Atlantic Ocean. Image in the infrared spectrum, July 1, 2020, for the 5-hour time slot, from 07:20 to 12:20 UTC, (Adapted) REDEMET, 2020). 
In Figure (3) the image of the CB moving to the Atlantic Ocean. Image in the infrared spectrum, July 1, 2020, for the 5-hour time slot, from 07:20 to 12:20 UTC. Adapted (REDEMET, 2020).

The Figure (3) shows an image in the infrared spectrum of the CB moving towards the high seas, that is, the Atlantic Ocean. The eye of the cyclone is crisp, and gains intensity when advancing towards the ocean. Image of the CB moving to the Atlantic Ocean, July 1, 2020, 07:20, 08:20, 09:20, 10:20, 11:20 to 12:20 UTC.

A high pressure area 1026 mbar, Figure (2), over Argentina coordinates $33^{\circ} \mathrm{S} 65^{\circ} \mathrm{W}$, moving in the direction to Paraguay. The synoptic chart in Figure (2) shows a 976 mbar low pressure center, coordinates $35^{\circ} \mathrm{S} 34^{\circ} \mathrm{W}$, next to Uruguay and Rio Grande do Sul coast, but away from the coast, 12:00 UTC on July 1, 2020.

The formation of the CB is clear, in Figures (3). An area of high pressure of 1022 mbar, over Argentina, with coordinates $35^{\circ} \mathrm{S} 65^{\circ} \mathrm{W}$, continuing its movement towards Paraguay, acquiring greater amplitude and intensity.

\section{3. "COTES'S SPIRAL" AND RESULTS}

As stated in the introduction the characteristic shape of hurricanes, cyclones, typhoons is a spiral (Vossler, 1999; Casey, 2001; Sharipov, ; León \& Rodrigues, 1989).

There are several types of turns, and determining the characteristic equation of which spiral the $\mathrm{CB}$ fits into is the goal of the work. In mathematics, a spiral is a curve which emanates from a point, moving farther away as it revolves around the point.

After an analysis of the different types of spirals (Fischer, 1993; Toomre, 1977; Oort, 1970; Nezlin \& Snezhkin, 1993; Gobato t al. (RG), 2020; Gobato t al. (RG1), 2020), it was found that the shape that came closest to the CB spiral, Figure (3), is a "Cotes's Spiral". (Fischer, 1993)

It was determined the mathematical equation of the shape of the extratropical cyclone, being in the shape of a spiral called "Cotes's Spiral" (Weisstein, 2020; Whittaker, 1944; Fischer, 1993).

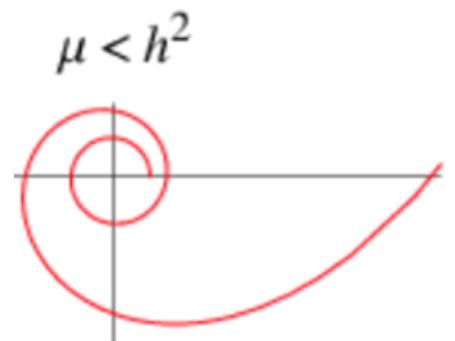

Figure 4. Spiral shape called "Cotes's Spiral." for $\mu<h^{2}$ (Weisstein, 2020; Whittaker, 1944). A spiral that gives the solution to the central orbit problem under a radial force law

$$
\ddot{r}=-\mu[r]^{-3} \hat{r}
$$

where $\mu$ is a positive constant. There are three solution regimes,

$$
r=\left\{\begin{array}{c}
A \sec (k \theta+\epsilon), \text { where } k^{2}=1-\frac{\mu}{h^{2}} \text { when } \mu<\mathrm{h}^{2} \\
A \cosh \left(k^{\prime} \theta+\epsilon\right), \text { where } k^{2}=\frac{\mu}{h^{2}}-1 \text { when } \mu>\mathrm{h}^{2} \\
A /(\theta+\epsilon), \text { when } \mu=\mathrm{h}^{2}
\end{array}\right.
$$


where $\boldsymbol{A}$ and $\boldsymbol{\epsilon}$ are constants, and $\boldsymbol{h}$ is the specific angular momentum (Whittaker, 1944; Fischer, 1993). The case $\boldsymbol{\mu}>\boldsymbol{h}^{2}$ gives an epispiral, while $\boldsymbol{\mu}=\boldsymbol{h}^{2}$ leads to a hyperbolic spiral.

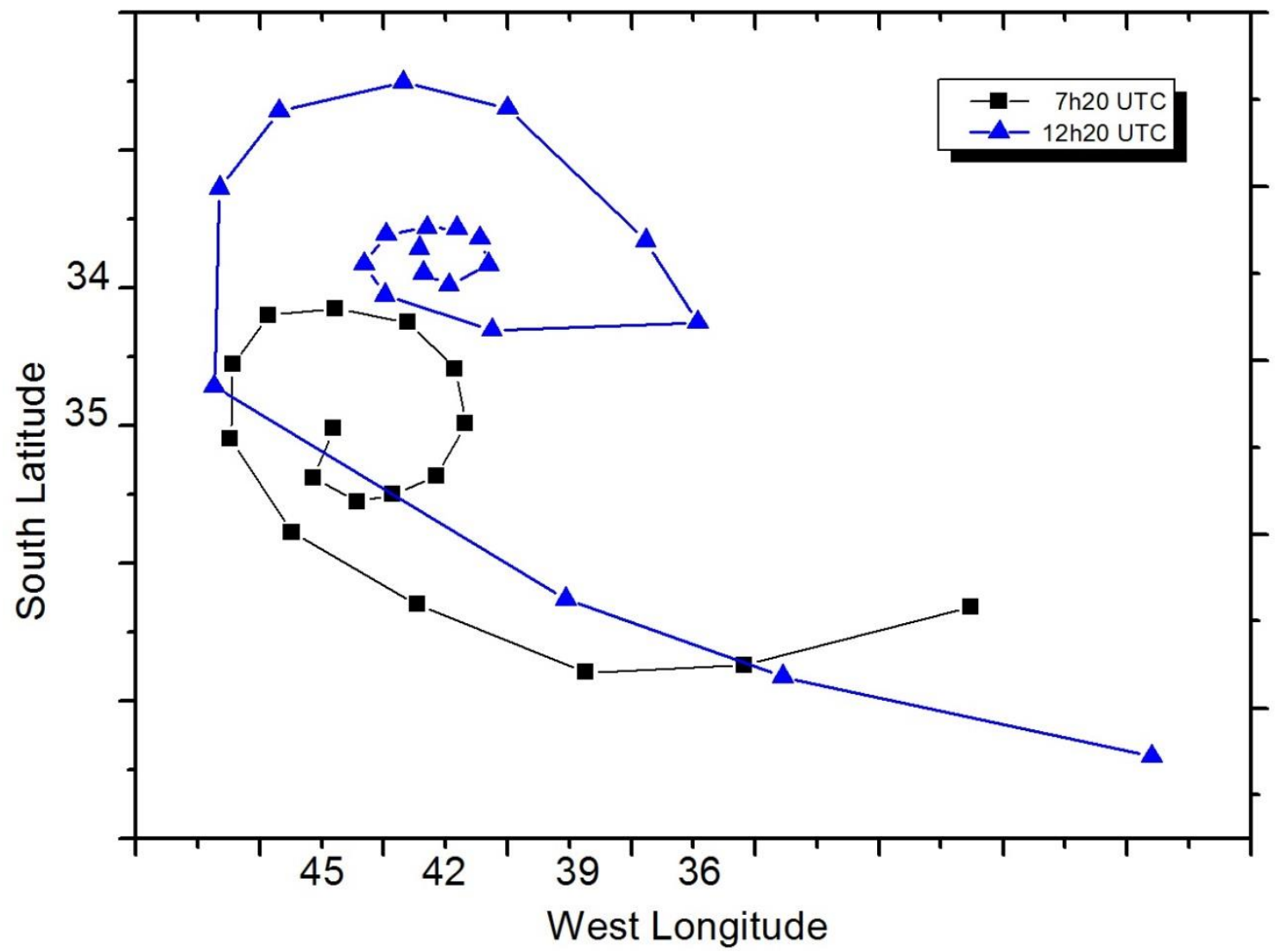

Figure 5. It represents the coordinates of the points collected from Figure (3), in Longitude and Latitude, using the Isobaric found in Figures (1) and (2). (Authors, 2020).

Figure (5) represents the coordinates of the points collected from Figure (3), in Longitude and Latitude. With the location of the low pressure center $(986 \mathrm{mbar})$ of the $\mathrm{CB}$ at $35^{\circ} \mathrm{S} 45^{\circ} \mathrm{W}$, at 07:20 UTC, and the low pressure center (972 mbar) of the $\mathrm{CB}$ at $35^{\circ} \mathrm{S} 42^{\circ} 30^{\prime} \mathrm{W}$, at $12: 20 \mathrm{UTC}$, Figures (1) and (2). In this Figure (5) the shape of the CB is represented, using as a parameter the isobaric ones observed in Figures (1) and (2).

Analyzing the shape of the Spiral shape called "Cotes's Spiral" for $\mu<h^{2}$ (Weisstein, 2020; Whittaker, 1944), it appears that adding two constants to Equation (3) makes the necessary adjustments for the Isobaric ones.

In the case of $\mathrm{CB}$, the spiral that gives the solution to a radial force law is given by Equation (1): $\ddot{r}=-\mu[r]^{-3} \hat{r}$, where:

$$
\boldsymbol{r}=\boldsymbol{A} \sec (\boldsymbol{k} \boldsymbol{\theta}+\boldsymbol{\epsilon}), \text { where } \boldsymbol{k}^{2}=\mathbf{1}-\frac{\boldsymbol{\mu}}{\boldsymbol{h}^{2}}, \text { when } \boldsymbol{\mu}<\mathbf{h}^{2} .
$$

An adjustment in Equation (3) is necessary to obtain the graph of Figure (5). Then, adding the constants $B \neq 0$ and $C$ where for $\mu<\mathrm{h}^{2}$.

$$
\begin{gathered}
r=B \cdot A \sec (k \theta+\epsilon)+C, \\
\text { where } k^{2}=1-\frac{\mu}{h^{2}}
\end{gathered}
$$




\section{Conclusion}

The occurrence of cyclones is relatively common for the southern region of Brazil at this time of year, that is, winter, but the recent phenomenon is augmented by other meteorological and atmospheric factors.

The CB generated a strong low pressure in its interior, creating two air streams which have worsened the phenomenon. An atmospheric current moved at high speed, in northwest-southeast direction, Bolivia, Paraguay, through the Paraná and Santa Catarina, and this airflow that hit the south of Brazil causing destruction. Another one traveled through Argentina in a southwestnortheast direction, colliding with the draft from Bolivia and Paraguay. Both of them clashed over the three southern states of Brazil. Only the outer edge of the CB reached the coast of the three states in the southern region of Brazil, Paraná, Santa Catarina and Rio Grande do Sul.

After an analysis of the different types of spirals, it was found that the shape that came closest to the CB spiral, is a "Cotes's Spiral". It was determined the mathematical equation of the shape of the extratropical cyclone, being in the shape of a spiral called "Cotes's Spiral".

In five hours the CB traveled a distance of $257.48 \mathrm{~km}$ (159.99 miles), at an average speed of $51.496 \mathrm{~km} / \mathrm{h}$ (31.998 miles/h) 27.81 knots, moved towards ENE, with a low pressure center of 986 mbar, 07:20 UTC, approximate location $35^{\circ} \mathrm{S} 45^{\circ} \mathrm{W}$, and 5 hours after 12:20 UTC had already grown and had a low pressure center of 972 mbar, approximate location $34^{\circ} \mathrm{S} 42^{\circ} 30^{\prime} \mathrm{W}$, using as a parameter the isobaric ones observed.

\section{References}

Alar Toomre. (1977). "Theories of Spiral Structure", Annual Review of Astronomy and Astrophysics 15(1):437-478. DOI: 10.1146/annurev.aa.15.090177.002253.

Chapecó. Creative Commons. (2020). CC BY-SA 3.0. https://creativecommons.org/licenses/bysa/3.0/ Available in: September 5, $2020 . \quad$ URL: https://en.wikipedia.org/wiki/Chapec\%C3\%B3

Crosta A. P. (1992). "Processamento digital de imagens de sensoriamento remoto". Campinas: IG/UNICAMP. $170 \mathrm{p}$.

de León M., and Rodrigues P. R. (1989). "Methods of Differential Geometry in Analytical Mechanics", Series: Mathematics Studies. Elsevier Science Ltd. ISBN: 0444880178,9780444880178 .

Donald L. Vossler. (1999). "Exploring Analytical Geometry with Mathematica", Academic Press, 1999. ISBN: $9780127282558,0127282556$.

Eric W. Weisstein. (2020). "Cotes's Spiral." From MathWorld--A Wolfram Web Resource. Available in: September $14, \quad 2020$ URL: https://mathworld.wolfram.com/CotesSpiral.html

Fischer R. (1993). "Fibonacci Applications and Strategies for Traders: Unveiling the Secret of the Logarithmic Spiral”, ISBN: 0471585203,9780471585206

Gobato R. and M. Simões F. (2017). "Alternative method of RGB channel spectroscopy using a CCD reader", Ciência e Natura, 39 202-210, 2017. DOI:10.5902/2179460X25617. 
Gobato R., Gobato A., Fedrigo D. F. G., (2016). "Study of tornadoes that have reached the state of Parana". Parana J. Sci. Educ., 2 (1): 1-27. doi.org/10.5281/zenodo.3783851. URL: https://sites.google.com/site/pjsciencea/2016/january-v-2-n-1

Howard B. Bluestein, Lance F. Bosart, Howard B. Bluestein (eds.). (2008). "Synoptic_-Dynamic Meteorology and Weather Analysis and Forecasting: A Tribute to Fred Sanders", Series: Meteorological Monographs 33, No. 55. American Meteorological Society. ISBN: 978-1878220-84-4,978-0-933876-68-2.

John Casey. (2001). "A treatise on the analytical geometry of the point, line, circle, and conic sections, containing an account of its most recent extensions, with numerous examples", University of Michigan Library. ISBN: 1418169897,9781418169893.

John David Anderson. (1984). "Fundamentals of Aerodynamics", McGraw-Hill Companies. ISBN: 9780070016569,0070016569

John P. Rafferty (2010). Storms, Violent Winds, and Earth's Atmosphere. Series: Dynamic Earth. Britannica Educational Publishing, Year: $2010 . \quad$ ISBN: $1615301143,9781615301140,1615301887,9781615301881$.

Joseph J. George. (1960). "Weather Forecasting for Aeronautics", Elsevier Inc, ISBN: 978-14832-3320-8

Krasny R. (1986), A study of singularity formation in a vortex sheet by the point vortex approximation, J. Fluid Mech. 167, 65-93.

Marius Paulescu, Eugenia Paulescu, Paul Gravila, Viorel Badescu. (2012). "Weather Modeling and Forecasting of PV Systems Operation”, Series: Green Energy and Technology, Springer. ISBN: $1447146484,9781447146483$.

Mikhail V. Nezlin, and Evgenii N. Snezhkin. (1993). "Rossby Vortices, Spiral Structures, Solitons: Astrophysics and Plasma Physics in Shallow Water Experiments", Series: Springer Series in Nonlinear Dynamics, Springer-Verlag Berlin Heidelberg. ISBN: 978-3-642-881244,978-3-642-88122-0

Navy Hydrography Center. Brazil's navy. Synoptic Letters. Available in: September 9, 2020. URL: $\quad$ https://www.marinha.mil.br/chm/dados-do-smm-cartas-sinoticas/cartassinoticas?field_data_value $\% 5 \mathrm{Bvalue} \% 5 \mathrm{D} \% 5 \mathrm{Bday} \% 5 \mathrm{D}=1 \&$ field data value $\% 5 \mathrm{Bvalue} \% 5 \mathrm{D}$ $\% 5 \mathrm{Bmonth} \% 5 \mathrm{D}=6 \&$ field_data_value $\% 5 \mathrm{Bv}$ alue $\% 5 \mathrm{D} \% 5 \mathrm{Byear} \% 5 \mathrm{D}=2020 \&$ field_horario_val ue $=12 \mathrm{HMG}$

Oort J. H. (auth.), Becker W., Contopoulos G. (eds.). (1970). "The Spiral Structure of Our Galaxy", Series: International Astronomical Union / Union Astronomique Internationale 38, Springer Netherlands. ISBN: 978-94-010-3277-3,978-94-010-3275-9

Patrick Santurette, Christo Georgiev. (2005). "Weather Analysis and Forecasting: Applying Satellite Water Vapor Imagery and Potential Vorticity Analysis", Academic Press. ISBN: $0126192626,9780126192629,9780080455266$

REDEMET, Rede de Meteorologia do Comando da Aeronáutica, (2020). GT-REDEMET, Imagens de Satélite, July 1, 2020, Available in: September 6, 2020, URL: https://www.redemet.aer.mil.br/index.php?i=produtos\&p=imagens-de-satelite 
Ricardo Gobato, Alireza Heidari, Abhijit Mitra, Marcia Regina Risso Gobato. (2020). "Cotes's Spiral Vortex in Extratropical Cyclone bomb South Atlantic Oceans", 2020-09-20, https://vixra.org/abs/2009.0144

Ricardo Gobato, Alireza Heidari. (2020) "Cyclone Bomb Hits Southern Brazil in 2020, Journal of Atmospheric Science Research”, V.3, n.3, July 2020. https://doi.org/10.30564/jasr.v3i3.2163

Ricardo Gobato; Alireza Heidari; Abhijit Mitra and Marcia Regina Risso Gobato, (2020). "Cotes's Spiral Vortex in Extratropical Cyclone bomb South Atlantic Oceans". DOI: 10.13140/RG.2.2.12778.95683. https://www.researchgate.net/publication/344322304_Cotes's_Spiral_Vortex_in_Extratropic al_Cyclone_bomb_South_Atlantic_Oceans

Ruslan Sharipov (2011). "Course of Analytical Geometry”, Bashkir State University (Russian Federation). ISBN: 978-5-7477-2574-4.

Saffman P. G. (1992). "Vortex dynamics. Series: Cambridge monographs on mechanics and applied mathematics", First Edition, Cambridge University Press.

Sokolovskiy M. A. and Verron J. (2000). "Four-vortex motion in the two layer approximation integrable case", $R X D$.

Stan Yorke. (2010) "Weather Forecasting Made Simple", Series: Countryside Books Reference. Countryside Books. ISBN: 1846741971,9781846741975

Tim Vasquez (2002). "Weather Forecasting Handbook" (5th Edition), Weather Graphics Technologies, ISBN: 0970684029,9780970684028.

Whittaker E. T. and Sir William McCrae. (1989). "Treatise on analytical dynamics of particles and rigid bodies", Cambridge Mathematical Library, Cambridge University Press, 1989. ISBN: 0521358833,9780521358835

Whittaker E. T. (1944). A Treatise on the Analytical Dynamics of Particles and Rigid Bodies: With an Introduction to the Problem of Three Bodies. New York: Dover, p. 83. 